\title{
FAKTOR- FAKTOR YANG MEMENGARUHI BIAYA USAHATANI
}

\section{Siti Walida Mustamin}

Prodi Hukum Ekonomi Syariah Unismuh Makassar || walidamustamin@ unimuh.ac.id

\begin{abstract}
Abstrak
Penelitian ini bertujuan untuk mengetahui faktor- faktor yang memengaruhi biaya usahatani padi di Kelurahan Wala Kecamatan Maritengngae Kabupaten Sidenreng Rappang. Penelitian ini terdiri dari satu variabel terikat yaitu biaya (Y) dengan variabel bebas yaitu biaya pupuk $\left(\mathrm{X}_{1}\right)$, upah tenaga kerja $\left(\mathrm{X}_{2}\right)$, biaya bibit, $\left(\mathrm{X}_{3}\right)$, biaya pestisida $\left(\mathrm{X}_{4}\right)$ dan produksi padi $\left(\mathrm{X}_{5}\right)$. Populasi dalam penelitian ini adalah seluruh petani padi yang ada di Kelurahan Wala Kecamatan Maritengngae Kabupaten Sidenreng Rappang yang berjumlah 600 orang kemudian dari jumlah tersebut ditarik sampel $10 \%$ sehingga diperoleh 60 orang responden. Teknik pengumpulan data yang digunakan dalam penelitian ini adalah observasi, dokumentasi, wawancara dan angket. Adapun teknik analisis data yang digunakan adalah analisis fungsi biaya coobdouglas, pengujian hipotesis dengan uji $\mathrm{f}$ dan uji t, dan pengukuran ketetapan model. Hasil penelitian menjelaskan bahwa Faktor- faktor yang berpengaruh signifikan secara positif terhadap biaya ushatani padi di Kelurahan Wala Kecamatan Maritengngae Kabupaten Sidenreng Rappang yaitu biaya pupuk, upah tenaga kerja, biaya bibit dan biaya pestisida. Sedangkan faktor yang berpengaruh signifikan secara negatif terhadap biaya usahatani padi di Kelurahan Wala Kecamatan Maritengngae Kabupaten Sidenreng Rappang yaitu produksi padi.
\end{abstract}

Kata Kunci : Biaya, upah tenaga kerja, biaya bibit, biaya pestisida, dan produksi padi. 


\begin{abstract}
This study aims to determine the factors that influence the cost of rice farming in Wala Village, Maritengngae District, Sidenreng Rappang Regency. This study consisted of one dependent variable namely cost $(Y)$ with independent variables namely fertilizer costs (X1), labor wages (X2), seed costs, (X3), pesticide costs (X4) and rice production (X5). The population in this study were all rice farmers in Wala Village, Maritengngae Subdistrict, Sidenreng Rappang District, totaling 600 people, then from that number a sample of $10 \%$ was withdrawn to obtain 60 respondents. Data collection techniques used in this study are observation, documentation, interviews and questionnaires. The data analysis technique used is the analysis of co-Douglas cost function, hypothesis testing with $f$ test and t-test, and measurement of model determination. The results of the study explain that the factors that have a significant positive effect on the cost of rice usahatani in Wala Village, Maritengngae Subdistrict, Sidenreng Rappang Regency are fertilizer costs, labor costs, seed costs, and pesticide costs. While the factors that have a significant negative effect on the cost of rice farming in Wala Village, Maritengngae District, Sidenreng Rappang Regency are rice production.
\end{abstract}

Keywords: Costs, labor wages, seed costs, pesticide costs, and rice production.

\section{PENDAHULUAN}

Sasaran utama pembangunan pertanian dewasa ini adalah peningkatan produksi pertanian dan pendapatan petani, karena itu kegiatan disektor pertanian diusahakan agar dapat berjalan lancar dengan peningkatan produk pangan baik melalui intensifikasi, ekstensifikasi, dan diversifikasi pertanian yang diharapakan dapat memperbaiki taraf hidup petani, memperluas lapangan pekerjaan bagi golongan masyarakat yang masih tergantung pada sektor pertanian.
Sektor pertanian merupakan sektor yang mempunyai peranan strategis dalam struktur pembangunan perekonomian nasional. Sektor ini merupakan sektor yang tidak mendapatkan perhatian secara serius dari pemerintah dalam pembangunan bangsa. Mulai dari proteksi, kredit hingga kebijakan lain tidak satu pun yang menguntungkan bagi sektor ini. Program- program pembangunan pertanian yang tidak terarah tujuannya bahkan semakin menjerumuskan sektor ini pada kehancuran. Meski demikian sektor ini merupakan sektor yang sangat 
banyak menampung luapan tenaga kerja dan sebagian besar penduduk Indonesia tergantung pada sektor pertanian.

Padi merupakan tanaman yang paling penting di negara Indonesia. Betapa tidak karena makanan pokok di Indonesia adalah nasi dari beras yang tentunya dihasilkan oleh tanaman padi. Padi merupakan salah satu komoditi yang mempunyai prospek cerah guna menambah pendapatan para petani. Hal tersebut dapat memberi motivasi tersendiri bagi petani untuk lebih mengembangkan dan meningkatkan produksinya dengan harapan agar pada saat panen usaha memperoleh hasil penjualan tinggi guna memenuhi kebutuhannya.

Perlu untuk diketahui bahwa kadang kala dalam kenyataannya yaitu dalam kehidupan sehari- hari ketika saat panen tiba, hasil melimpah tetapi harga mendadak turun, dan lebih parah lagi jika hasil produksi yang telah diprediksikan jauh melenceng dari jumlah produksi yang dihasilkan, produksi minim, harga rendah dan tidak menentu membuat petani padi kadang merasa kecewa bahkan patah semangat untuk tetap megembangkan usaha pertaniannya. Hal ini disebabkan karena setiap kegiatan pengolahan sawah mutlak petani mengeluarkan biaya untuk kegiatan produksi, mulai dari pengadaan bibit, pupuk, pengolahan, pestisida dan biaya lainnya yang tidak terduga.

Menurut Sidiq Hanapi (2010), mengatakan bahwa pendapatan rata-rata usahatani padi sawah irigasi di salah satu sentra produksi padi di Kecamatan Belitang III, Kabupaten Ogan Komering Ulu Timur per hektar sebesar Rp.8.911.338,24. Sedangkan faktorfaktor yang mempengaruhi tingkat keuntungan usahatani padi sawah irigasi adalah luas tanam, harga GKP, harga pupuk Urea, harga pestisida dan jumlah produksi padi. Sedangkan menurut Edi Marsudi dan Mustafa Usman, (2009) bahwa faktor luas lahan, biaya produksi berpengaruh nyata terhadap pendapatan usahatani padi sawah Hibrida Arize R1 dan faktor tenaga kerja tidak berpengaruh nyata terhadap pendapatan usahatani padi sawah Hibrida Arize R1.

Kabupaten Sidenreng Rappang dianggap sebagai Produsen Utama Komoditas Pertanian. Kabupaten ini merupakan Produsen/ Pengekspor beras paling besar di Sulawesi Selatan yang 
sangat berpotensial dengan usaha tani padi karena didukung oleh iklim, sarana serta struktur tanah. Adapun produksi padi di Kabupaten Sidenreng Rappang pada tahun 2010 mencapai 62.208,62 ton terkonsentrasi pada Kecamatan Maritengngae.

Naik turunya produksi padi yang ada di Kecamatan Maritengngae Kabupaten Sidenreng Rappang tergantung pada faktor- faktor produksi yang digunakan baik secara langsung maupun tidak langsung. Hal ini pula yang mengakibatkan terjadinya perubahan (naik/turun) biaya usaha tani padi di Kelurahan Wala Kecamatan Maritengngae Kabupaten Sidenreng Rappang. Sehubungan dengan uraian tersebut, maka judul "Analisis terhadap Faktor- Faktor yang Memengaruhi Biaya Usahatani Padi di Kelurahan Wala Kecamatan Maritengngae Kabupaten Sidenreng Rappang "menarik untuk dikaji.

\section{METODE PENELITIAN}

1. Lokasi dan Rancangan Penelitian Penelitian ini dilaksanakan di Kelurahan Wala Kecamatan Maritengngae Kabupaten Sidenreng Rappang Provinsi Sulawesi Selatan.
Metode Penelitian yang digunakan dalam penelitian ini adalah metode deskriptif dan eksplanatori. Menurut Singarimbun dan Effendi (1989) dalam Rahim (2010:78) bahwa deskriptive method (metode deskriptif) dimaksudkan untuk pengukuran yang cermat terhadap fenomena sosial, sedangkan penelitian yang menjelaskan hubungan antara variabel-variabel melalui pengujian hipotesis disebut explanatory research (penelitian penjelasan). Berkaitan dengan deskriptive method, mendeskripsikan besarnya biaya usahatani padi di Kelurahan Wala Kecamatan Maritengngae Kabupaten Sidenreng Rappang. Kemudian explanatory method, menguji dan menganalisis model analisis faktor-faktor yang memengaruhi biaya dan pendapatan usahatani padi di Kelurahan Wala Kecamatan Maritengngae Kabupaten Sidenreng Rappang.

2. Teknik Pengumpulan Data

Dalam penelitian ini peneliti menggunakan teknik pengumpulan data berupa Observasi yaitu cara pengumpulan data dengan mengamati langsung dilapangan. Selanjutnya Dokumentasi yaitu cara penumpulan 
data dengan jalan mengumpulkan data melalui keterangan secara tertulis yang merupakan dokumen-dokumen yang ada hubungannya dengan data yang dibutuhkan dalam penelitian. Wawancara Kegiatan yang dilakukan peneliti dengan teknik wawancara ini adalah mewawancarai secara langsung petani padi yang menjadi responden dalam hal ini apapun yang menyangkut padi berupa jumlah produksi, jumlah tenaga kerja, upah yang diberikan kepada tenaga kerja, harga padi dan sebagainya. Angket yaitu suatu teknik atau alat pengumpulan data dengan jalan mengajukan daftar pertanyaan mengenai masalah yang hendak diteliti kepada responden untuk dijawab.

3. Teknik Analisa Data

Untuk menganalisis faktor-faktor yang memengaruhi biaya usahatani padi di Kelurahan Wala Kecamatan Maritengngae Kabupaten Sidenreng Rappang maka digunakan fungsi biaya Coob-Douglas secara matematik dapat dituliskan sebagaimana yang dikemukakan oleh Soekartawi (1994:24) dalam Rahim dan Diah (2007:59) sebagai berikut :

$$
\begin{aligned}
\text { CUP } & =\beta_{0} \operatorname{CPpk}^{\beta 1} \mathrm{UTk}^{\beta 2} \mathrm{CBbt}^{\beta 3} \mathrm{CPst}^{\beta 4} \\
& \mathrm{YUp}^{\beta 5} \mathrm{e}
\end{aligned}
$$

Untuk memudahkan pendugaan terhadap persamaan di atas maka persamaan tersebut dapat di ubah dalam bentuk double log (ln) sebagai berikut : LnCUP $=\beta_{0}+\beta_{1}$ LnCPpk $+\beta_{2}$ LnUTk $+\beta_{3} \mathrm{LnCBbt}+\beta_{4}$ CPst $+\beta_{5}$ Yup $\mathrm{e}_{1}$

Keterangan :

LnCUP : Biaya usahatani padi (Rp)

$\beta_{0} \quad$ : Konstanta/intercept

$\beta_{1, .} \beta_{5} \quad$ : Koefisien arah regresi

$\beta_{1}$ CPpk : Biaya pupuk (Rp)

$\beta_{2}$ UTk : Upah tenaga (Rp)

$\beta_{3} \mathrm{CBbt}$ : Biaya bibit (Rp)

$\beta_{4}$ CPst : Biaya pestisida (Rp)

$\beta_{5}$ YUp : Produksi padi (Kg)

$\mathrm{e}_{1} \quad$ : Gangguan error

\section{HASIL PENELITIAN}

Dalam penelitian ini terdapat 5 faktor yang memengaruhi biaya usahatani padi di Kelurahan Wala Kecamatan Maritengngae Kabupaten Sidenreng Rappang yaitu biaya pupuk, upah tenaga kerja, biaya bibit, biaya pestisida dan produksi padi. Dalam penelitian ini, analisis data yang digunakan adalah analisis statistik fungsi biaya Coob-Douglas. 
Tabel 1 Analisis $\quad$ Faktor- Maritengngae Kabupaten

Faktor yang Memengaruhi Sidenreng Rappang, Tahun Biaya Usahatani Padi di 2012

\section{Kelurahan Wala Kecamatan}

\begin{tabular}{llrrr}
\hline Variabel Independen & \multicolumn{1}{l}{ TH } & $\boldsymbol{\beta}$ & t- Hitung & \multicolumn{1}{l}{ Sign } \\
\hline Biaya Pupuk & + & $0,132^{* * *}$ & 11,791 & 0,000 \\
Upah Tenaga Kerja & + & $0,717^{* * *}$ & 25,078 & 0,000 \\
Biaya Bibit & + & $0,060^{* * *}$ & 5,395 & 0,000 \\
Biaya Pestisida & + & $0,132^{* * *}$ & 6,543 & 0,000 \\
Produksi Padi & + & $-0,061^{* *}$ & $-2,055$ & 0,045 \\
\hline Konstanta & & & & 0,950 \\
\hline f- Hitung & & & 6473,917 \\
\hline Sign f & & & 0,000 \\
\hline $\mathrm{R}$ & & & 0,998 \\
\hline
\end{tabular}

Sumber : Analsis Data Primer Setelah di Olah, 2012

Keterangan :

TH : Tanda Harapan

*** : Taraf signifikan dan kesalahan 0 ,

$01 \quad(1 \%)$ atau tingkat kepercayaan $99 \%$

** : Taraf signifikan dan kesalahan 0 , $05(5 \%)$ atau tingkat kepercayaan $95 \%$

Taraf siginifikan merupakan taraf kepercayaan. Dalam penelitian ini menggunakan dua taraf yaitu : taraf kepercayaan atau taraf signifikan 0,01 (1\%) artinya taraf kebenarannya adalah 99 persen dan tingkat kesalahannya 1 persen dan yang kedua adalah taraf kepercayaan atau taraf signifikan 0,05 (5\%) artinya taraf kebenarannya adalah 95 persen dan tingkat kesalahannya 5 persen. Jika memperhatikan kembali bentuk persamaan setelah menarik logaritma natural dari persamaan regresi

fungsi Coob-Douglas, yaitu :

$\mathrm{LnCUP}=0,950+0,132 \mathrm{LnCPpk}+$ 0,717 LnUTk $+0,060$ LnCBbt + 0,132 LnCPst 0,061 LnYUP + e ...... (IV.1)

Dari persamaan IV.1, maka persamaan tersebut diubah kembali menjadi persamaan fungsi biaya coobdouglas dengan meng- anti Ln kan sebagai berikut :

CUP $=$ Anti Ln 0,950 $\mathrm{CPpk}^{0,132} \mathrm{UTk}^{0,717}$

$$
\mathrm{CBbt}^{0,060} \mathrm{CPst}^{0,132}
$$

$\mathrm{YUP}^{0,061} \mathrm{e}$

$\mathrm{CUP}=2,586 \mathrm{CPpk}^{0,132} \mathrm{UTk}^{0,717}$ $\mathrm{CBbt}^{0,060} \mathrm{CPst}^{0,132}$

$\mathrm{YUP}^{0,061} \mathrm{e}$ (IV.3) 
Untuk mengetahui keberkaitan koefesien regresi maka dilakukan uji f, adapun uji f yang dimaksud dapat dilihat pada tabel 4.18. Tabel 4.18 menunjukkan bahwa nilai f- Hitung sebesar 6473,917 dengan signifikansi 0,000 jauh lebih kecil dari taraf kepercayaan yang digunakan yaitu 0,01, dengan demikian dapat disimpulkan bahwa $\mathrm{H}_{\mathrm{o}}$ ditolak dan H1diterima. Hal ini berarti variabel independen ( biaya pupuk, upah tenaga kerja, biaya bibit, biaya pestisida dan produksi padi ) secara bersama- sama ( simultan ) berpengaruh nyata terhadap variabel dependen ( biaya usahatani padi di Kelurahan Wala Kecamatan Maritengngae Kabupaten Sidenreng Rappang ).

Adapun untuk melihat nilai koefesien regresi determinasi $\left(\mathrm{R}^{2}\right)$, maka dapat dilihat pada tabel 4.18 di mana nilai koefesien regresi determinasi $\left(\mathrm{R}^{2}\right)$ sebesar 0,998 berarti variansi faktor biaya pupuk, upah tenaga kerja, biaya bibit, biaya pestisida dan produksi padi memberikan sumbangan atau kontribusi sebesar 99,8 persen terhadap naik turunnya biaya usahatani padi di $\begin{array}{llr}\text { Kelurahan } & \text { Wala } & \text { Kecamatan } \\ \text { Maritengngae } & \text { Kabupaten } & \text { Sidenreng }\end{array}$
Rappang, sedangkan lainnya 0,2 persen merupakan sumbangan dari faktor lainnya yang tidak termasuk dalam penelitian ini.

Adapun nilai konstanta pada tabel 4.18 adalah 0,950 dimana nilainya itu menandakan bahwa jika biaya pupuk $\left(\mathrm{X}_{1}\right)$, upah tenaga kerja $\left(\mathrm{X}_{2}\right)$, biaya bibit $\left(\mathrm{X}_{3}\right)$, biaya pestisida $\left(\mathrm{X}_{4}\right)$ dan produksi padi $\left(\mathrm{X}_{5}\right)$ tidak ada atau $\mathrm{X}_{1}, \mathrm{X}_{2}, \mathrm{X}_{3}, \mathrm{X}_{4}$ dan $X_{5}=0$, maka biaya usahatani padi di Kelurahan Wala Kecamatan Maritengngae Kabupaten Sidenreng Rappang adalah sebesar 0,950 rupiah.

Untuk mengetahui faktor- faktor yang berpengaruh terhadap biaya usahatani padi di Kelurahan Wala Kecamatan Maritengngae Kabupaten Sidenreng Rappang maka di uji dengan menggunakan uji t. Adapun faktor biaya usahatani padi dalam penelitian ini yang di uji dengan menggunakan uji t adalah sebagai berikut :

a. Biaya Pupuk

Berdasarkan tabel 4.18 biaya pupuk berpengaruh signifikan secara positif terhadap biaya usahatani padi di Kelurahan Wala Kecamatan Maritengngae Kabupaten Sidenreng Rappang dengan nilai t- Hitung sebesar 11,791 , nilai koefesien $\beta$ yaitu 0,132 dan 
tingkat signifikansi 0,000 jauh lebih kecil dari taraf signifikansi yang digunakan yaitu $0,01(1 \%)$, artinya jika terjadi kenaikan biaya pupuk, maka biaya usahatani padi di Kelurahan Wala Kecamatan Maritengngae Kabupaten Sidenreng Rappang akan meningkat, hal ini sesuai dengan hipotesis yang diajukan. Selanjutnya koefesien regresi sebesar 0,132 yang berarti setiap penambahan biaya pupuk kepada usahatani padi sebesar 1 rupiah maka akan meningkatkan biaya usahtani padi sebesar 0,132 rupiah.

b. Upah Tenaga Kerja

Hasil analisis upah tenaga kerja sesuai dengan tabel 4.18 , upah tenaga kerja berpengaruh signifikan secara positif terhadap biaya usahatani padi di Kelurahan Wala Kecamatan Maritengngae Kabupaten Sidenreng Rappang dengan t- Hitung 25,078, nilai koefesien $\beta$ yaitu 0,717 dan tingkat signifikansi 0,000, jauh lebih kecil dari taraf signifikansi yang digunakan yaitu 0,01 (1\%), artinya upah tenaga kerja mempunyai pengaruh yang signifikan terhadap biaya usahatani padi di Kelurahan Wala Kecamatan Maritengngae Kabupaten Sidenreng Rappang, hal ini sesuai dengan hipotesis yang diajukan, di mana jika terjadi kenaikan upah tenaga kerja maka biaya usahatani padi akan meningkat. Selanjutnya koefesien regresi sebesar 0,717 yang berarti setiap penambahan upah tenaga kerja sebesar 1 rupiah maka akan meningkatkan biaya usahatani padi sebesar 0,717 rupiah.

c. Biaya Bibit

Berdasarkan tabel 4.18 biaya bibit berpengaruh signifikan secara positif terhadap biaya usahatani padi di Kelurahan Wala Kecamatan Maritengngae Kabupaten Sidenreng Rappang dengan t- Hitung 5,395, nilai koefesien $\beta$ yaitu 0,060 dan tingkat signifikansi 0,000, jauh lebih kecil dari taraf signifikansi yang digunakan yaitu $0,01(1 \%)$, artinya biaya bibit mempuyai pengaruh yang signifikan terhadap biaya usahatani padi di Kelurahan Wala Kecamatan Maritengngae Kabupaten Sidenreng Rappang, hal ini sesuai dengan hipotesis yang diajukan, di mana jika terjadi kenaikan biaya bibit maka akan terjadi peningkatan biaya usahatani padi. Selanjutnya koefesien regresi sebesar 0,060 yang berarti setiap penambahan biaya bibit kepada usahatani padi sebesar 1 rupiah maka 
akan meningkatkan biaya usahatani padi sebesar 0,060 rupiah.

\section{d. Biaya Pestisida}

Hasil analisis biaya pestisida sesuai dengan tabel 4.18 , biaya pestisida berpengaruh signifikan secara positif terhadap biaya usahatani padi di Kelurahan Wala Kecamatan Maritengngae Kabupaten Sidenreng Rappang dengan t- Hitung 6,543, nilai koefesien $\beta$ yaitu 0,132 dan tingkat signifikansi 0,000, jauh lebih kecil dari taraf signifikansi yang digunakan yaitu $0,01(1 \%)$, artinya biaya pestisida mempunyai pengaruh yang signifikan terhadap biaya usahatani padi di Kelurahan Wala Kecamatan Maritengngae Kabupaten Sidenreng Rappang, hal ini sesuai dengan hipotesis yang diajukan. Selanjutnya keofesien regresi sebesar 0,132 yang berarti setiap penambahan biaya pestisida kepada usahatani padi sebesar 1 rupiah maka akan meningkatkan biaya usahatani padi sebesar 0,132 rupiah.

e. Produksi Padi

Berdasarkan tabel 4.18, produksi padi berpengaruh signifikan secara negatif terhadap biaya usahatani padi di $\begin{array}{llr}\text { Kelurahan } & \text { Wala } & \text { Kecamatan } \\ \text { Maritengngae } & \text { Kabupaten } & \text { Sidenreng }\end{array}$
Rappang dengan t- Hitung -2,055 nilai koefesien $\beta$ yaitu $-0,061$ dan tingkat signifikansi 0,045 dimana lebih kecil dari taraf signifikansi yang digunakan yaitu $0,05(5 \%)$, artinya produksi padi mempuyai pengaruh yang signifikan terhadap biaya usahatani padi di Kelurahan Wala Kecamatan Maritengngae Kabupaten Sidenreng Rappang. Selanjutnya koefesien regresi yaitu $-0,061$ yang berarti setiap peningkatan produksi padi kepada usahatani padi sebesar 5 persen maka akan menurunkan biaya usahatani padi sebesar -0,061. Hal ini berbeda dengan tanda positif yang diharapkan, yaitu semakin banyak produksi padi yang dihasilkan oleh petani padi maka biaya usahatani padi akan meningkat pula akibat meningkatnya produksi padi.

\section{KESIMPULAN}

Hasil penelitian ini menunjukkan bawah faktor- faktor yang berpengaruh signifikan secara positif terhadap biaya usaha tani padi di Kelurahan Wala Kecamatan Maritengngae Kabupaten Sidenreng Rappang yaitu biaya pupuk, upah tenaga kerja, biaya bibit dan biaya pestisida. Sedangkan faktor yang berpengaruh signifikan secara negatif 
terhadap biaya usahatani padi di Maritengngae Kabupaten Sidenreng Kelurahan Wala Kecamatan Rappang yaitu produksi padi.

\section{DAFTAR PUSTAKA}

Ahmad S.Pd. 2004. Analisis Pendapatan Usaha Tani Padi di Kelurahan Bontoa Kecamatan Mandai Kabupaten Maros. Skripsi Universitas Negeri Makassar.

Anas M Fauzi dan Arif Satria. 2008. Agenda Riset Pangan. Institut Pertanian Bogor.

Arikunto, Suharsimi. 2006. Prosedur Penelitian Suatu Pendekatan Praktik. Jakarta: Rineka Cipta.

Biro Pusat Statistik. 2011. Dinas Pertanian Kabupaten Sidenreng Rappang.

Hanapi, Sidiq. 2010. Analisis Pendapatan dan Faktor Keuntungan Usahatani Padi Sawah Irigasi di Sumatera Selatan. Hasil- hasil penelitian dan Pengkajian. Palembang.

Munarfa Andi, M, Hasan. 2009. Metode Penelitian. Makassar: Peraktika Aksara Semesta.

Rahim. 2010. Analisis Harga Ikan Laut Segar dan Pendapatan Usaha Tangkap Nelayan di Sulawesi Selatan. Disertasi S-3 Program Pasca Serjana, Fakultas Pertanian, Program Studi Ekonomi Pertania, Universitas Gadjah Mada, Yogyakarta.

Rahim, A., dan D.R.D.Hastuti. 2007. Ekonomika Pertanian (Pengantar, Teori, dan Kasus). Penebar Swadaya, Jakarta.

Rahim, A., Supardi, Suprapti, D.R.D. Hastuti. 2012. Model Analisis Ekonomika Pertanian, Badan Penerbit UNM, Makassar.

Sharma, A.N., dan V.K. Sharma. 1981. Elements of Farm Management, Prentice Hall of India Private, New Delh.

Soekartawi, 1994, Teori Ekonomi Produksi dengan Pokok Bahasan Analisis Fungsi Cobb-Douglas. PT RajaGrafindo Persada, Jakarta.

Soekartawi. 2002. Prinsip Dasar Ekonomi Pertanian: Teori dan Aplikasi. Edisi Revisi 2002. Raja-Grafindo Persada, Jakarta.

Sugiyono. 2011. Metode Penelitian Kombinasi, Yogyakarta: PT Alfabeta Bandung.

Sukirno, S. 2004. Pengantar Teori Mikroekonomi (Edisi ketiga), Rajawali Press Jakarta.

Widodo, S. 1993. Ilmu Ekonomi Pertanian dan Pembangunan, Pidato Pengukuhan Jabatan Guru Besar dalam Ekonomika Pertanian. Fakultas Pertanian Universitas Gadjah Mada, Jogjakarta. 